\title{
Faster Arctic Sea Ice Retreat in CMIP5 than in CMIP3 due to Volcanoes
}

\author{
ERICA ROSENBLUM AND IAN EISENMAN \\ Scripps Institution of Oceanography, University of California, San Diego, La Jolla, California
}

(Manuscript received 24 May 2016, in final form 4 October 2016)

\begin{abstract}
The downward trend in Arctic sea ice extent is one of the most dramatic signals of climate change during recent decades. Comprehensive climate models have struggled to reproduce this trend, typically simulating a slower rate of sea ice retreat than has been observed. However, this bias has been widely noted to have decreased in models participating in phase 5 of the Coupled Model Intercomparison Project (CMIP5) compared with the previous generation of models (CMIP3). Here simulations are examined from both CMIP3 and CMIP5. It is found that simulated historical sea ice trends are influenced by volcanic forcing, which was included in all of the CMIP5 models but in only about half of the CMIP3 models. The volcanic forcing causes temporary simulated cooling in the 1980s and 1990s, which contributes to raising the simulated 1979-2013 global-mean surface temperature trends to values substantially larger than observed. It is shown that this warming bias is accompanied by an enhanced rate of Arctic sea ice retreat and hence a simulated sea ice trend that is closer to the observed value, which is consistent with previous findings of an approximately linear relationship between sea ice extent and global-mean surface temperature. Both generations of climate models are found to simulate Arctic sea ice that is substantially less sensitive to global warming than has been observed. The results imply that much of the difference in Arctic sea ice trends between CMIP3 and CMIP5 occurred because of the inclusion of volcanic forcing, rather than improved sea ice physics or model resolution.
\end{abstract}

\section{Introduction}

Modeling groups from around the world have contributed state-of-the-art climate model simulation results to the Coupled Model Intercomparison Project (CMIP). Simulations of the historical period have natural and anthropogenic forcing and can be compared with the instrumental record to assess how well the climate models perform. These simulations are then extended to project future climate change using several different greenhouse gas concentration trajectories. There have been several CMIP phases as comprehensive climate models have continued to be developed. The two most recent phases have been phase 3 (CMIP3; Meehl et al. 2007) and phase 5 (CMIP5; Taylor et al. 2012), which were used to project future climate change in the Intergovernmental Panel on Climate Change (IPCC) Fourth and Fifth Assessment Reports (AR4 and AR5), respectively.

The historical simulations have shown substantial bias in reproducing Arctic sea ice changes during the satellite

Supplemental information related to this paper is available at the Journals Online website: http://dx.doi.org/10.1175/JCLI-D-16-0391.s1.

Corresponding author e-mail: Erica Rosenblum, ejrosenb@ucsd.edu record, with the models typically simulating a slower rate of sea ice retreat than has been observed (Stroeve et al. 2007, 2012; Winton 2011; Kay et al. 2011; Swart et al. 2015). However, CMIP5 models tend to simulate faster sea ice trends that are more consistent with observations than CMIP3 (Stroeve et al. 2012), as illustrated in Figs. $1 \mathrm{~b}$ and 1c. This has been a widely discussed feature of CMIP5, and it was highlighted in the executive summary of the IPCC AR5 chapter on the evaluation of climate models (Flato et al. 2013). However, the cause of this apparent improvement has remained unresolved.

Here we focus on the influence of historical volcanic forcing, which was included in all of the CMIP5 models but only about half of the CMIP3 models. Volcanic eruptions perturb the climate by injecting gases into the stratosphere that produce short-lived sulfate aerosols that reflect and absorb solar radiation. This causes rapid global surface cooling that spans approximately two to three years, which

Publisher's Note: This article was revised on 13 September 2017 to note that the cited reference to Rosenblum and Eisenman (2016), which was not yet in press at the time the time of original publication, refers to the following article: Rosenblum, E., and I. Eisenman, 2017: Sea ice trends in climate models only accurate in runs with biased global warming. J. Climate, 30, 6265-6278, https://doi.org/10.1175/JCLI-D-16-0455.1. 

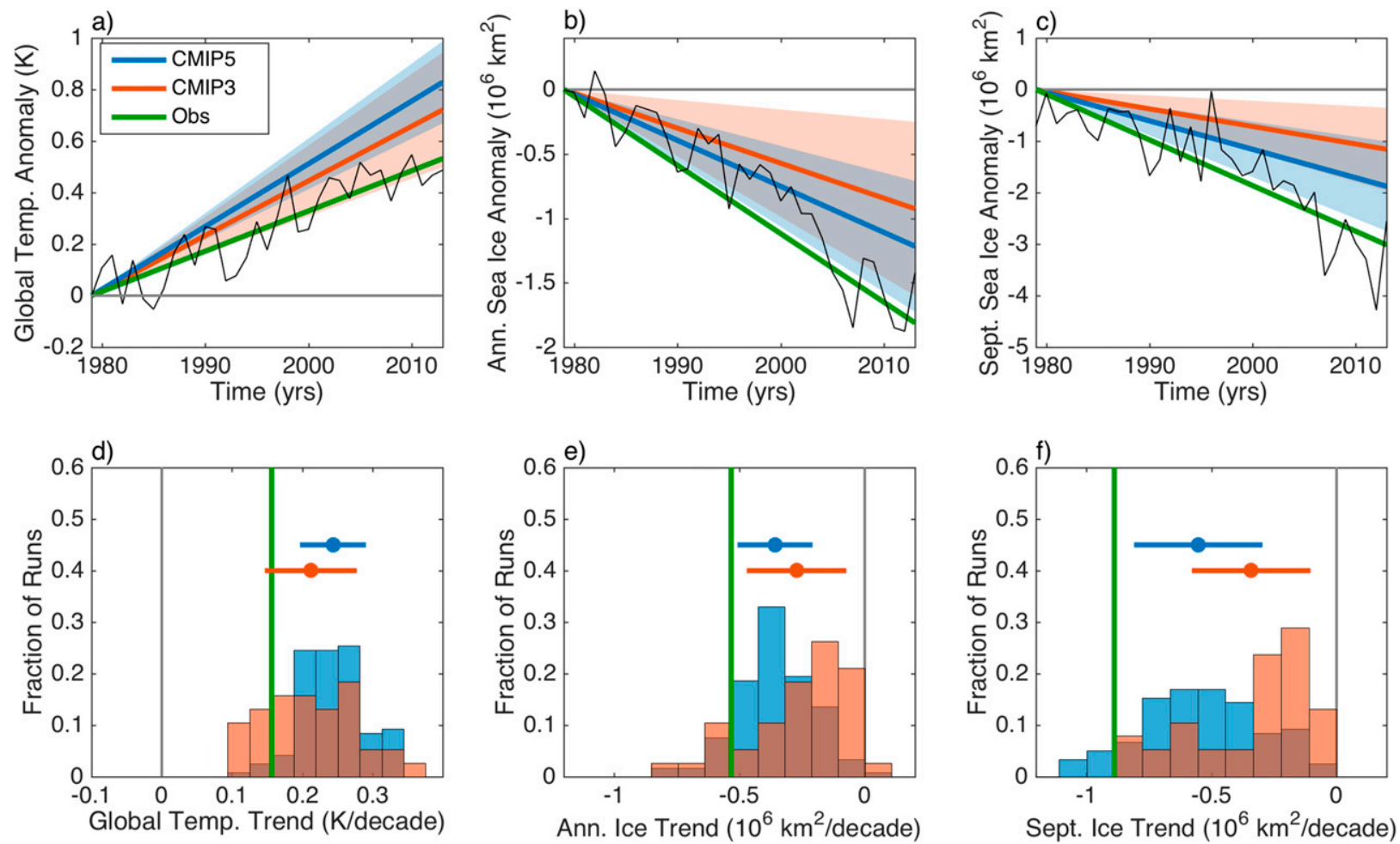

FIG. 1. Observed as well as CMIP3 and CMIP5 modeled trends in (a),(d) annual-mean global-mean surface temperature; (b),(e) annualmean Arctic sea ice extent; and (c),(f) September Arctic sea ice extent. (top) Trends are illustrated as straight lines indicating the anomaly from 1979, with shadings indicating one std dev among the CMIP3 or CMIP5 trends around the ensemble means. The observed time series is also included in each panel (black, shifted vertically so linear trend goes through zero in 1979). (bottom) Histograms illustrating the distributions of CMIP3 and CMIP5 trends. Std devs among the distributions around the ensemble means are indicated by blue and red error bars above the distributions, and the observed trends are indicated by vertical green lines.

is followed by a decade-long warming period during which the climate recovers (IPCC 2013). This cooling due to volcanic eruptions has been found to be overestimated in climate models compared with observations, which can cause biases in simulated decade-scale trends (Schmidt et al. 2014; Santer et al. 2014). The CMIP3 models that include volcanic forcing tend to simulate global-mean surface air temperature changes that are fairly similar to the CMIP5 models, whereas CMIP3 models without volcanic forcing simulate global-mean surface air temperature changes that differ substantially from the CMIP5 simulations (e.g., Schmidt et al. 2014; Knutson et al. 2013; Marotzke and Forster 2015).

Arctic sea ice extent has been found to be approximately linearly related to global-mean surface temperature in many of the CMIP3 and CMIP5 models (Gregory et al. 2002; Winton 2011; Mahlstein and Knutti 2012; Stroeve and Notz 2015), including over periods as brief as 19792013 (Rosenblum and Eisenman 2016). This implies that volcano-related biases in simulated global warming during recent decades should be associated with biases in sea ice retreat. Consistent with this, a number of studies have shown that volcanic forcing in climate model simulations can influence Arctic sea ice for a decade or more (Stenchikov et al. 2009; Zhong et al. 2011; Zanchettin et al. 2012, 2013; Segschneider et al. 2013; Zanchettin et al. 2014). Taken together, the results of these previous studies raise the possibility that the inclusion of volcanic forcing in all of the CMIP5 models compared to only some of the CMIP3 models could have caused a systematic change in the distribution of simulated sea ice trends.

We examine this effect by analyzing simulations of 1979 2013 in 118 ensemble members from 40 CMIP5 models, as well as 38 ensemble members from 19 CMIP3 models, and comparing them with observations (see details in the appendix). We use processed CMIP5 output from a separate study (Rosenblum and Eisenman 2016), where we addressed whether simulated natural variability was sufficient to explain the biases in the CMIP5 ensemble-mean Arctic and Antarctic sea ice trends compared with observations.

\section{Results}

The distributions of September Arctic sea ice trends during 1979-2013 in the CMIP3 and CMIP5 simulations 

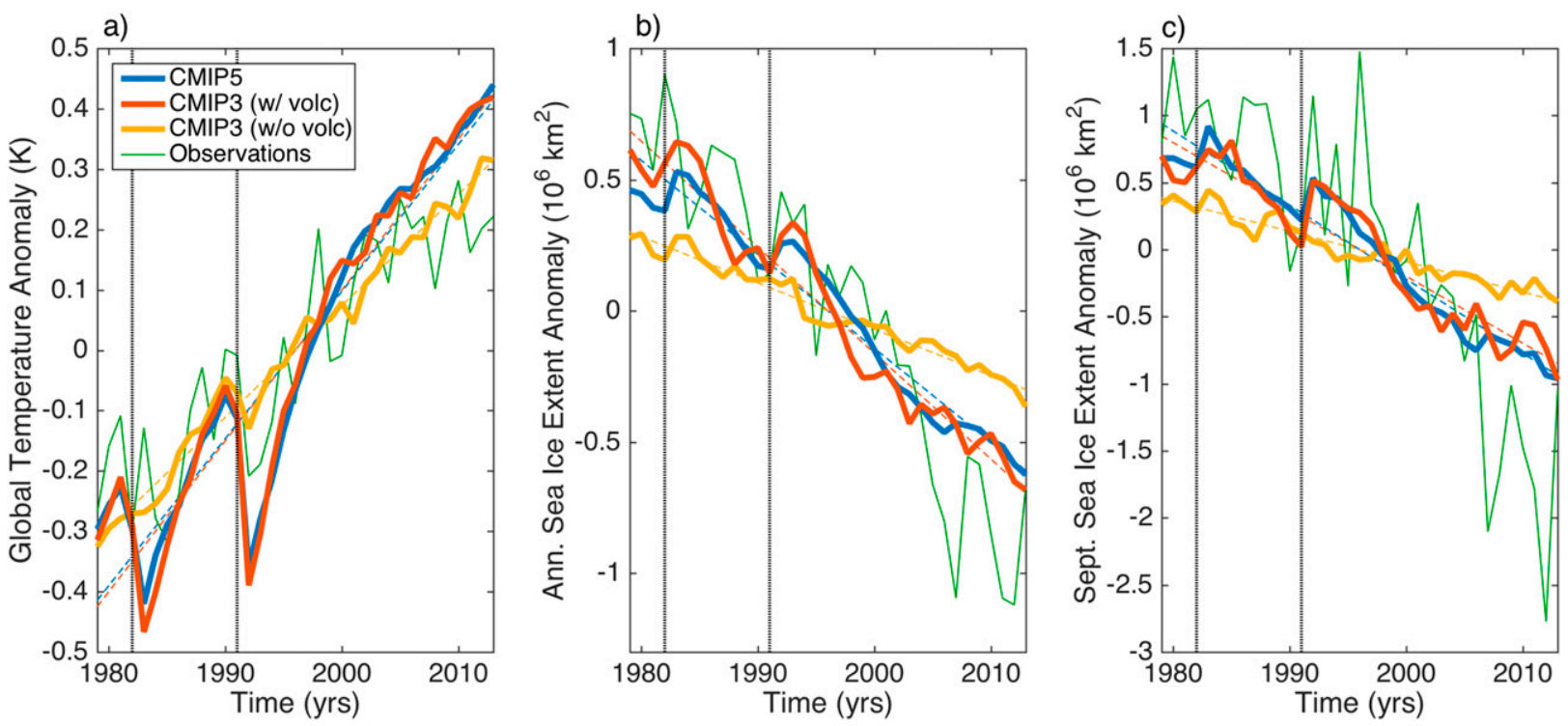

FIG. 2. Observed and modeled (a) annual-mean global-mean surface temperature, (b) annual-mean Arctic sea ice extent, and (c) September Arctic sea ice extent. Anomalies from the average value during the plotted time period are shown for the observations (green), the CMIP5 ensemble mean (blue), and the ensemble mean of CMIP3 models with (red) and without (yellow) volcanic forcing. The linear trend associated with each time series is also indicated (dashed lines). This figure illustrates how the cooling effects associated with the eruptions of El Chichón (1982) and Pinatubo (1991) (vertical dotted lines) result in faster global-mean temperature trends and in faster sea ice trends.

are plotted in Figs. 1c and 1f. CMIP5 models tend to simulate a faster September Arctic sea ice retreat, which has a reduced bias compared with observations, as has been reported previously (Stroeve et al. 2012; Flato et al. 2013). The annual-mean sea ice trend behaves similarly (Figs. 1b,e), with the ensemble mean falling closer to the observations in CMIP5 than in CMIP3.

It is noteworthy, however, that this decrease in bias in the simulated Arctic sea ice trend coincides with an increase in bias in the simulated annual-mean global-mean surface temperature trend compared to the observations during the same time period (Figs. 1a,d). Although both generations of models tend to simulate too much warming, the observed global temperature trend during 1979-2013 falls less than one standard deviation below the mean in the CMIP3 distribution, whereas the CMIP5 distribution has a larger bias (error bars in Fig. 1d).

This warming bias is partially related to both generations of models having a tendency to simulate too much global warming during the past 10-20 years, which has been attributed to a number of factors including internal variability (IPCC 2013; Kosaka and Xie 2013; Fyfe et al. 2013). Additionally, the temperature trend during 19792013 is expected to be influenced by the eruptions of El Chichón in 1982 and Pinatubo in 1991. These events cause surface cooling in the 1980s and 1990s that has been found to be overestimated in climate models (Schmidt et al. 2014; Knutson et al. 2013; Marotzke and Forster 2015). Figure 2a illustrates that the large negative temperature anomalies caused by these volcanoes lead to a larger overall warming trend during this period. This suggests that one reason the CMIP5 ensemble-mean global warming trend during 1979-2013 is farther from the observations than in CMIP3 (Figs. 1a,d) is because volcanic forcing is included in all of the CMIP5 models compared to about half of the CMIP3 models (Fig. 2a and Table 1).

As expected from the approximately linear relationship between sea ice cover and annual-mean global-mean surface air temperature in many CMIP3 and CMIP5 models (Gregory et al. 2002; Winton 2011; Mahlstein and Knutti 2012; Stroeve and Notz 2015; Rosenblum and Eisenman 2016), we find that the large negative temperature anomalies that are caused by simulated volcanic forcing are associated with concurrent positive sea ice cover anomalies (Fig. 2). Similarly, we find that the decade-long warming periods following each eruption typically correspond with a drop in sea ice cover (Fig. 2). Because these eruptions occur toward the beginning of the 1979-2013 period, they contribute to a larger overall rate of sea ice retreat (dashed lines in Figs. 2b,c). Therefore the bias in the models toward too much 1979-2013 global warming, which is elevated by volcanic forcing, appears to be associated with the larger simulated sea ice trends.

Consistent with this, we find that the major eruptions before 1979 in the CMIP3 and CMIP5 historical forcing scenarios are typically followed by a brief increase in the September and annual-mean Arctic sea ice extent 
TABLE 1. For each CMIP3 model, the number of runs, 1979-2013 annual-mean global-mean surface temperature trend (K decade ${ }^{-1}$ ) averaged over the runs, and 1979-2013 annual-mean and September Arctic sea ice trends $\left(10^{6} \mathrm{~km}^{2}\right.$ decade $\left.{ }^{-1}\right)$ averaged over the runs is listed. See http://www-pcmdi.llnl.gov/ipcc/model_documentation/ipcc_model_documentation.php for a list of the modeling centers associated with each CMIP3 model listed here. Note that similar information for the CMIP5 models is given in Table 1 of Rosenblum and Eisenman (2016).

\begin{tabular}{|c|c|c|c|c|}
\hline & No. of simulations & $\begin{array}{c}\text { Annual global } \\
\text { temp trend }\end{array}$ & $\begin{array}{l}\text { Annual sea } \\
\text { ice trend }\end{array}$ & $\begin{array}{l}\text { September sea } \\
\text { ice trend }\end{array}$ \\
\hline \multicolumn{5}{|l|}{ Models with volcanic forcing } \\
\hline GFDL CM2.0 & 1 & 0.27 & -0.72 & -0.59 \\
\hline GFDL CM2.1 & 1 & 0.28 & -0.51 & -0.68 \\
\hline GISS-ER & 1 & 0.20 & -0.14 & -0.20 \\
\hline MIROC3.2 (hires) & 1 & 0.34 & -0.54 & -0.73 \\
\hline MIROC3.2 (medres) & 3 & 0.20 & -0.26 & -0.32 \\
\hline MIUBECHOG & 3 & 0.21 & -0.28 & -0.34 \\
\hline CCSM3 & 5 & 0.29 & -0.45 & -0.60 \\
\hline HadGEM1 & 1 & 0.25 & -0.50 & -0.67 \\
\hline All models with volcanic forcing & 16 & 0.25 & -0.39 & -0.49 \\
\hline \multicolumn{5}{|l|}{ Models without volcanic forcing } \\
\hline BCCR-BCM2.0 & 1 & 0.14 & -0.27 & -0.35 \\
\hline CGCM3.1 & 5 & 0.24 & -0.15 & -0.18 \\
\hline CGCM3.1 (T63) & 1 & 0.29 & -0.23 & -0.24 \\
\hline CNRM-CM3 & 1 & 0.17 & 0.02 & -0.25 \\
\hline CSIRO Mk3.5 & 1 & 0.21 & -0.15 & -0.26 \\
\hline GISS-AOM & 2 & 0.14 & -0.17 & -0.23 \\
\hline INM-CM3.0 & 1 & 0.26 & -0.40 & -0.53 \\
\hline IPSL-CM4 & 1 & 0.28 & -0.49 & -0.58 \\
\hline MPI-ECHAM5 & 3 & 0.15 & -0.21 & -0.22 \\
\hline MRI-CGCM2.3.2a & 5 & 0.13 & -0.10 & -0.11 \\
\hline HadCM3 & 1 & 0.16 & -0.20 & -0.29 \\
\hline All models without volcanic forcing & 22 & 0.18 & -0.18 & -0.23 \\
\hline
\end{tabular}

(Fig. S1 in the supplemental material). Overall, this simulated historical Arctic sea ice response to volcanic eruptions is in agreement with previous modeling studies (Segschneider et al. 2013; Zanchettin et al. 2012; Stenchikov et al. 2009; Zanchettin et al. 2014).

By comparing CMIP5 models with the subset of CMIP3 models that include volcanic forcing, we find that both ensembles predict a more similar distribution of both global warming trends and sea ice trends (Figs. 3a-c) than when all CMIP3 models are included (Figs. 1d-f). Indeed, this difference in simulated volcanic forcing is typically accounted for in studies that compare simulated global warming between CMIP3 and CMIP5 (e.g., Knutson et al. 2013; Watanabe et al. 2013; Knutti and Sedláček 2012).

Note that the influence of volcanoes is statistically significant in the CMIP3 results (red and yellow error bars in Figs. 3a-c): using the Student's $t$ test, we can reject the null hypothesis that the two sets of CMIP3
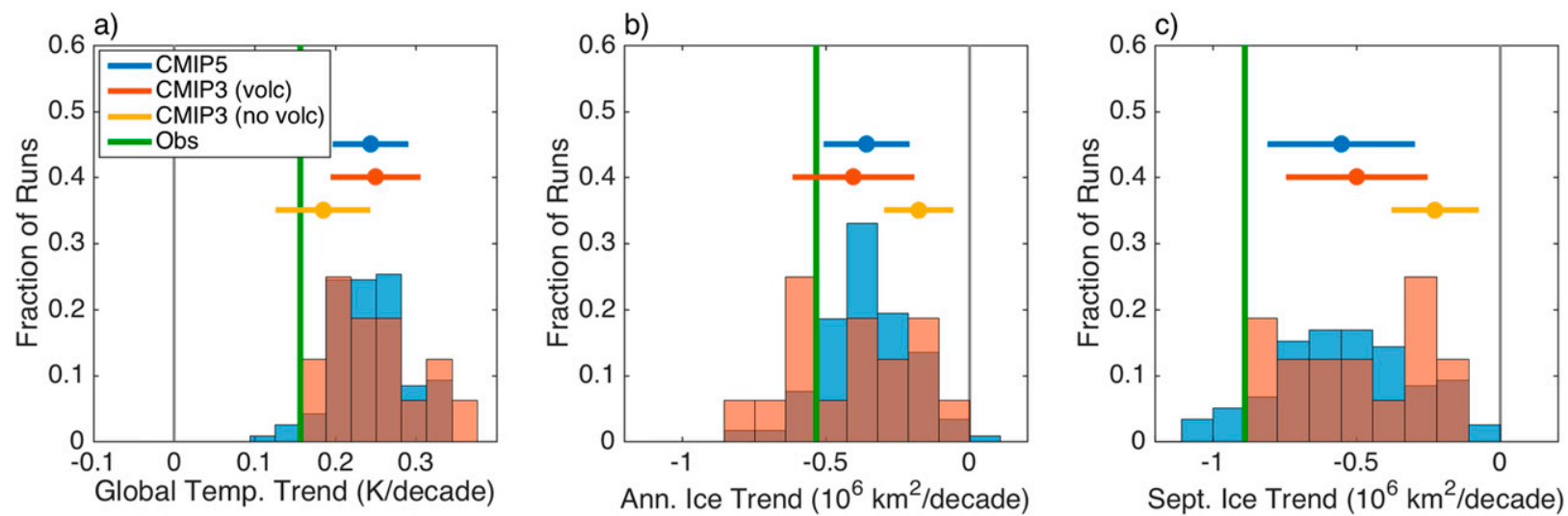

FIG. 3. As in Figs. 1d-f, but using only the subset of CMIP3 simulations that include volcanic forcing. The ensemble mean and std dev of the CMIP3 simulations that do not include volcanic forcing are also indicated (yellow error bar). 
models simulate temperature trends that are drawn from distributions with the same mean at above the $99.9 \%$ confidence level, and the same applies to the annual and September sea ice trends. It should be noted by caveat that this assessment relies on the relatively small ensemble of CMIP3 models that included volcanic forcing.

\section{Discussion}

Here we examine the results presented above in the context of the sea ice sensitivity to global warming (Winton 2011), drawing on methods developed in a separate study (Rosenblum and Eisenman 2016).

\section{a. Do volcanoes influence sea ice sensitivity?}

The results above suggest that volcanic forcing artificially improved simulated sea ice trends by raising the level of global warming to values larger than observed. A simple interpretation of this is that the sea ice responds to the inclusion of volcanoes just as it does if the level of global warming increases due to other factors such as greenhouse gases or internal variability. Here we assess this possibility by investigating whether the inclusion of volcanic forcing affects the sensitivity of the simulated sea ice cover to the level of global warming, or whether this sensitivity remains constant.

As in Rosenblum and Eisenman (2016), we consider the possibility that the relationship between global warming trends and sea ice trends remains approximately constant during all 35-yr periods between 1900 and 2100 (which would exactly hold if this relationship were perfectly linear). We construct two distributions of 35 -yr sea ice trends and associated global-mean surface air temperature trends from models that include volcanic forcing: (i) using years 1979-2013 and (ii) using all available overlapping 35-yr periods during 1900-2100 that are not within 10 years of a major volcanic event (i.e., Santa Maria in 1902, Agung in 1963, El Chichón in 1982, and Pinatubo in 1991). The first distribution is meant to characterize the distribution of sea ice trends that occur under global warming including the effects of volcanic forcing, while the second characterizes the distribution of sea ice trends that occur in the same models in the absence of volcanic forcing.

In Fig. 4, the Arctic sea ice trend is plotted versus the annual-mean global-mean surface temperature trend, with each point representing a $35-\mathrm{yr}$ period in a simulation and colors representing the two distributions. By comparing the two distributions in each panel, we find that the influence of volcanic forcing has no visibly discernible impact on the sensitivity of the Arctic sea ice extent to the level of global warming. That is, for a given value on the horizontal axis in each panel of Fig. 4, the blue points tend to be scattered around approximately the same vertical range as the red points, indicating that 35 -yr periods that undergo similar levels of global warming to those simulated for 1979-2013 typically have similar sea ice trends, even without volcanic eruptions. This implies that the influence of volcanic forcing on simulated sea ice trends can be approximately accounted for by considering only the effect on globalmean surface temperatures.

\section{b. Comparing CMIP3 and CMIP5 sea ice sensitivities}

The relationship between global-mean surface air temperature and Arctic sea ice extent implies that biases in simulated global warming trends should be associated with biases in sea ice trends (Winton 2011). Therefore, similar to Rosenblum and Eisenman (2016), we examine the Arctic sea ice trend in each simulation versus the global-mean surface temperature trend. We find that both CMIP3 models and CMIP5 models that simulate faster (hence more accurate) annual-mean sea ice trends also tend to simulate larger (hence less accurate) global warming trends (Fig. 5a and Table 1). While the CMIP3 models with volcanic forcing tend to fall in a different region of the scatterplot than those without volcanic forcing (consistent with Fig. 3), the points all fall near the same line. We find similar results using September sea ice trends (Fig. 5b and Table 1), although this relationship appears noisier, perhaps due to a larger influence of internal variability.

We can approximately account for biases in the level of global warming by considering the Arctic "effective sea ice trend" (Rosenblum and Eisenman 2016), which is defined as the simulated sea ice trend scaled by the bias in simulated global warming during the same time period [where the latter is calculated as the ratio of observed to simulated annual-mean global-mean surface temperature trend; see the appendix herein and also Rosenblum and Eisenman (2016) for details]. The effective sea ice trend is closely related to the sea ice sensitivity (Winton 2011). It provides a rough estimate of what the sea ice trend would be in each run if the observed level of global warming had been simulated.

By comparing the distributions of modeled effective Arctic sea ice trends to the observed trend, the results in Figs. $5 \mathrm{c}$ and $5 \mathrm{~d}$ suggest that the modeled Arctic sea ice cover in both CMIP3 and CMIP5 would retreat far more gradually if the models simulated the observed level of global warming (see also Table 2, which includes both effective sea ice trends and sea ice sensitivities). The effective sea ice trend in CMIP5 is slightly closer to the observations than in CMIP3, especially in September, but the observed trend falls well outside both CMIP model distributions. 

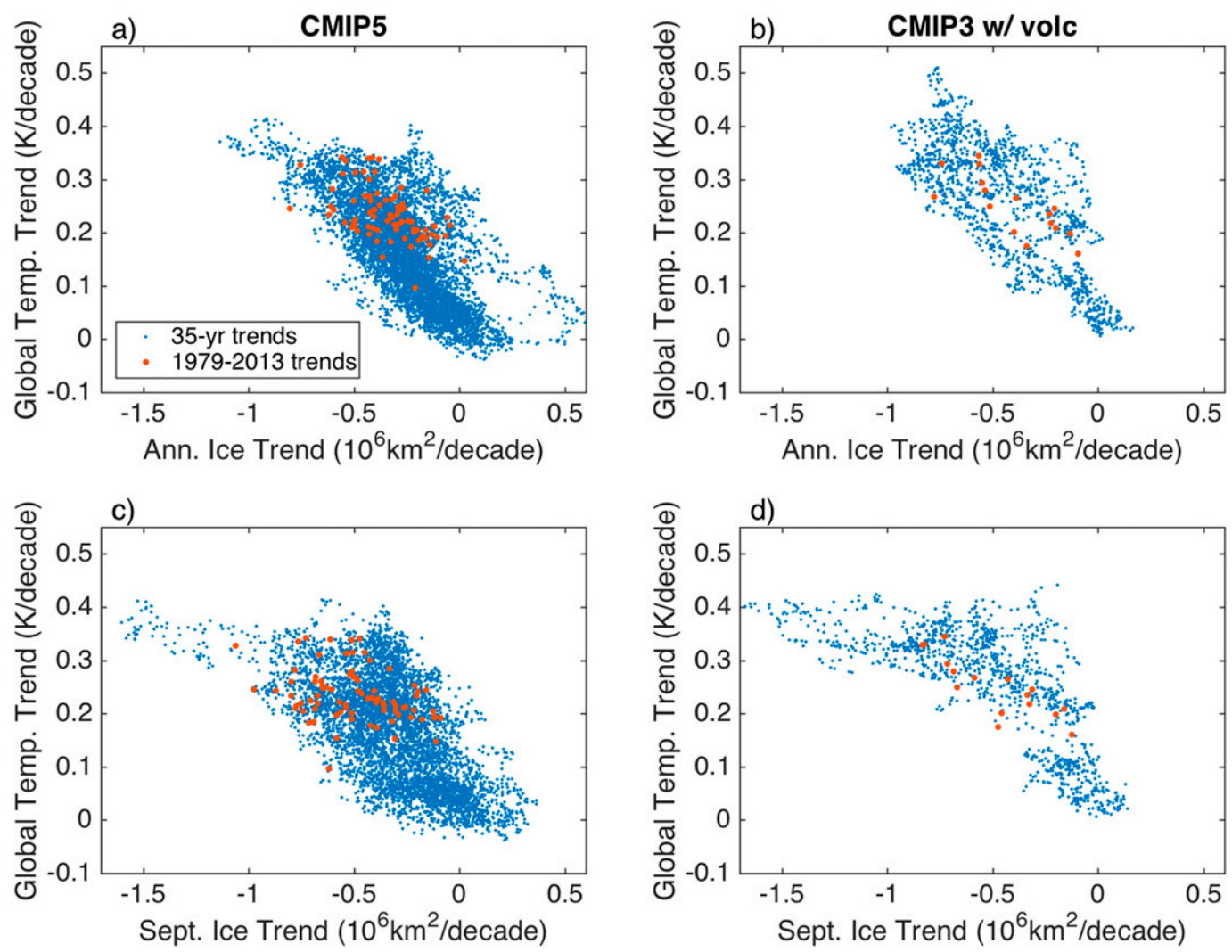

FIG. 4. Simulated 35-yr annual-mean global-mean surface air temperature trends plotted vs (top) annual-mean and (bottom) September Arctic sea ice trends for (left) CMIP5 and (right) CMIP3 models that included volcanic forcing. Trends from 1979 to 2013 are indicated in red, and all available 35-yr time periods between 1900 and 2100 that were not within 10 years of a major volcanic event are indicated in blue. The major volcanic events are Santa Maria in 1902, Agung in 1963, El Chichón in 1982, and Pinatubo in 1991.

Note that this bias in simulated sea ice sensitivity is qualitatively consistent with Stroeve and Notz (2016), although there are quantitative differences due to factors including the availability of CMIP5 results at the time of each analysis and differing methods used to estimate the ice sensitivity (see the appendix). The possibility that simulated natural variability could explain this bias is examined in a separate paper (Rosenblum and Eisenman 2016).

\section{Additional points}

Although the Southern Hemisphere sea ice extent and annual-mean global-mean surface air temperature are also approximately linearly related in these climate models (Rosenblum and Eisenman 2016), we find that the influence of volcanoes does not appear to have the same impact on the evolution of Antarctic sea ice (Fig. S2 in the supplemental material). This may be related to a range of factors, including that the aerosol forcing from both Pinatubo and El Chichón is more concentrated in the Northern Hemisphere than the Southern Hemisphere in many datasets (Arfeuille et al. 2014), that in the Southern Ocean much of the temperature change caused by volcanoes has been suggested to occur at depth (Fyfe 2006), that Antarctic sea ice has been suggested to only respond to supervolcanoes (Zanchettin et al. 2014), and that Antarctic sea ice extent is less correlated with annual-mean global-mean surface air temperature than Arctic sea ice extent (Rosenblum and Eisenman 2016).

Previous studies have demonstrated that CMIP5 models simulate a smaller and more accurate climatological Arctic sea ice cover compared to CMIP3 (Stroeve et al. 2012; Flato et al. 2013). The possibility that this could be linked to sea ice trends has been considered previously, although no clear relationship was found (Massonnet et al. 2012). Similarly, we find that the initial sea ice cover does not appear to be closely related to the sea ice trends (Fig. S3 in the supplemental material). This is consistent with the approximately linear relationship between simulated Arctic sea ice cover and annual-mean global-mean 

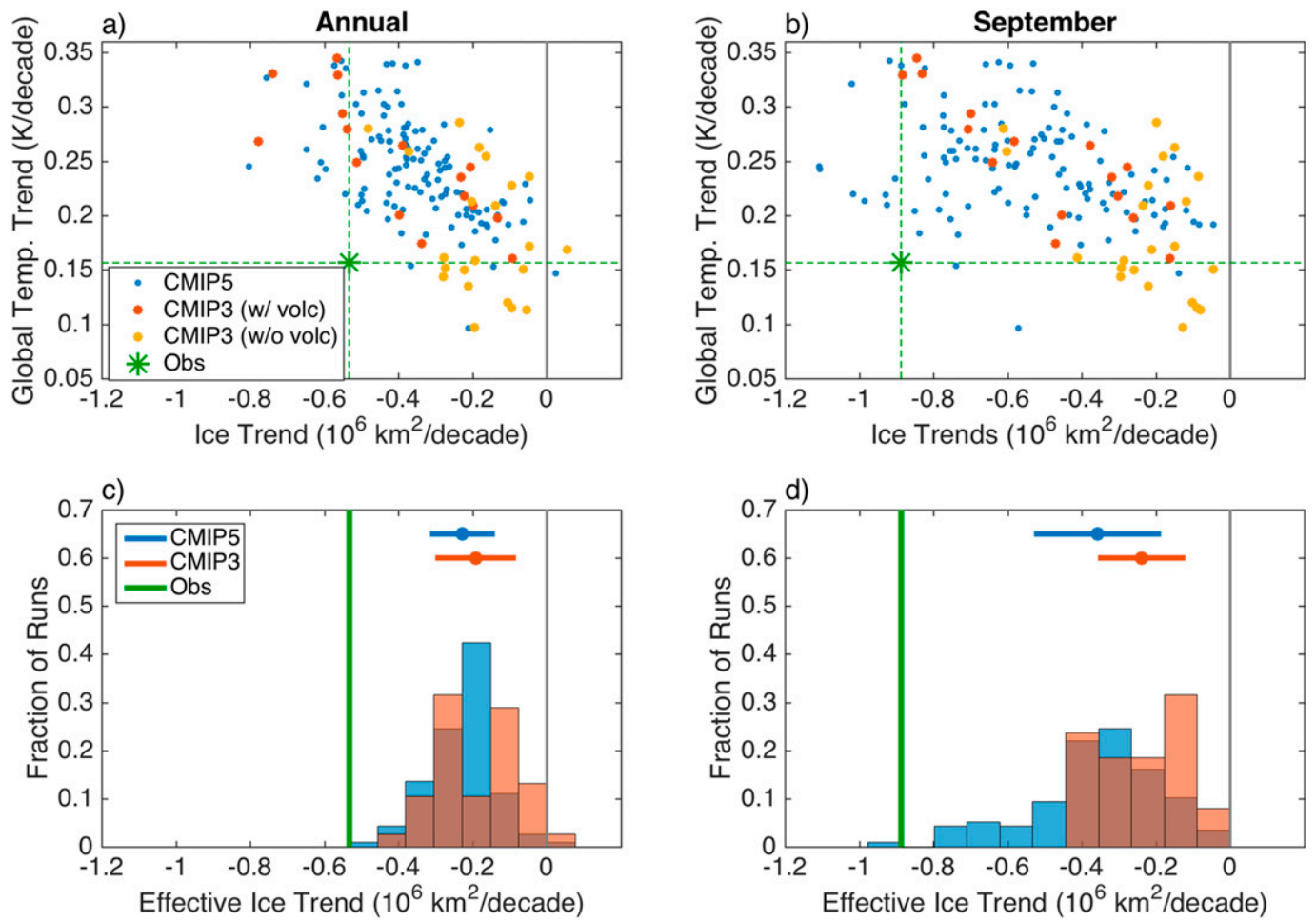

FIG. 5. Observed and modeled annual-mean global-mean surface temperature trends plotted vs (a) annual-mean and (b) September Arctic sea ice trends. CMIP5 models (blue), CMIP3 models with volcanic forcing (red), and CMIP3 models without volcanic forcing (yellow) are plotted, and dashed green lines represent the observed trend. The histograms show the Arctic (c) annual-mean and (d) September effective sea ice trends (see text for details), with the observed trend indicated by a thick green line. Std devs of the distributions around the ensemble means are also indicated. Note that the histograms in Figs. $1 \mathrm{~b}$ and 1c describe the distributions of horizontal coordinate values in Figs. 5a and $5 b$.

surface temperatures (Gregory et al. 2002; Winton 2011; Mahlstein and Knutti 2012; Stroeve and Notz 2015; Rosenblum and Eisenman 2016). That is, if this were a perfectly linear relationship, a given amount of warming would result in the same amount of ice loss regardless of the initial amount of sea ice cover. Note that although geographic muting effects due to the distribution of landmasses in the Arctic region (Eisenman 2010) can cause a departure from this linearity for very large ice extents [Fig. S2 of Armour et al. (2011)], the relationship has been found to be approximately linear for annual-mean and September ice extents similar to and smaller than modern observed values [e.g., Fig. 2 of Armour et al. (2011)].

The main results of this study are presented using sea ice extent (Figs. 2-5). We find that analyzing observed and modeled sea ice area instead of extent leads to qualitatively similar results (Figs. S4-S8 in the supplemental material).

Our estimate of the observed September sea ice sensitivity $\left(-5.67 \times 10^{6} \mathrm{~km}^{2} \mathrm{~K}^{-1}\right)$ is more than twice as large as the number reported previously by Mahlstein and Knutti (2012) $\left(-2.62 \times 10^{6} \mathrm{~km}^{2} \mathrm{~K}^{-1}\right)$, who used the ice sensitivity to make an observationally based projection of how much global warming it would take for the September Arctic sea ice area to decline from its 1980-99 mean value to the nearly ice-free value of $1 \times 10^{6} \mathrm{~km}^{2}$. The difference between our estimate and that in Mahlstein and Knutti (2012) arises due to a number of factors. We use NASA Team sea ice extent (Fetterer et al. 2002) during 1979-2013. By contrast, Mahlstein and Knutti (2012) use the coarser-resolution

TABLE 2. Observed as well as CMIP3 and CMIP5 ensemblemean effective sea ice trends $\left(10^{6} \mathrm{~km}^{2}\right.$ decade $\left.^{-1}\right)$ and sea ice sensitivity $\left(10^{6} \mathrm{~km}^{2} \mathrm{~K}^{-1}\right)$ as shown in Fig. 5 are listed. Std devs among the ensemble members are indicated in parentheses. Note that the ice sensitivity is equal to the effective ice trend divided by the observed temperature trend, which is $0.16 \mathrm{~K} \mathrm{decade}^{-1}$.

\begin{tabular}{llllll}
\hline \hline & \multicolumn{2}{c}{ Effective ice trend } & & \multicolumn{2}{c}{ Ice sensitivity } \\
\cline { 2 - 3 } \cline { 5 - 6 } & \multicolumn{1}{c}{ Annual } & September & & Annual & September \\
\hline CMIP3 & $-0.19(0.11)$ & $-0.24(0.12)$ & & $-1.23(0.69)$ & $-1.53(0.75)$ \\
CMIP5 & $-0.23(0.09)$ & $-0.36(0.17)$ & & $-1.46(0.56)$ & $-2.29(1.10)$ \\
Obs & -0.53 & -0.89 & -3.40 & -5.67 \\
\hline
\end{tabular}


Hadley Centre Sea Ice and Sea Surface Temperature dataset (HadISST; Rayner et al. 2003), the observed ice area rather than ice extent, and a shorter observed time period (1980-2007). Further, they calculate the ice sensitivity using an ordinary least squares regression of ice on temperature (I. Mahlstein 2016, personal communication), which Winton (2011) found to give a less accurate estimate than the trend ratio method adopted here (see the appendix).

Using CMIP3 simulations, Mahlstein and Knutti (2012) found that the ensemble-mean ice sensitivity during 2010-2100 was smaller than during 1980-2007 by a factor of 0.92 , and hence they scaled the observed ice sensitivity by 0.92 to project the level of future global warming at which the Arctic will become nearly seasonally ice free. We repeat the calculation from Mahlstein and Knutti (2012) using an observed ice sensitivity of $-5.67 \times 10^{6} \mathrm{~km}^{2} \mathrm{~K}^{-1}$ and the 1980-99 mean September Arctic sea ice extent from the NASA Team dataset, rather than an observed sensitivity of $-2.62 \times 10^{6} \mathrm{~km}^{2} \mathrm{~K}^{-1}$ and the 1980-99 mean September Arctic sea ice area from HadISST. We find that in this case the level of global warming projected to cause a nearly ice-free Arctic Ocean is approximately $1{ }^{\circ} \mathrm{C}$ above the $1980-99$ average, rather than approximately $2^{\circ} \mathrm{C}$ as reported in Mahlstein and Knutti (2012). Using the NASA Team ice area rather than ice extent for the observed sensitivity and the 1980-99 mean value yields a similar result of approximately $1^{\circ} \mathrm{C}$.

\section{Summary}

CMIP5 models have been found to simulate Arctic sea ice retreat during 1979-2013 that is faster on average than in the CMIP3 models. At the same time, the CMIP5 ensemble-mean rate of global warming during 19792013 has been found to be larger than that in CMIP3. The difference in global warming has been previously attributed to historical volcanic forcing, which was included in all of the CMIP5 models but only about half of the CMIP3 models. However, the inclusion of volcanic forcing in the CMIP ensembles has not been considered, as far as the authors are aware, in previous analyses of the rate of simulated Arctic sea ice retreat. Here we show that a range of approaches all suggest that the change between CMIP5 and CMIP3 in the ensemblemean 1979-2013 Arctic sea ice extent trend can also be largely attributed to the inclusion of volcanic forcing.

Specifically, major volcanic eruptions occur during the early part of this time period, and they cause temporary cooling and ice expansion. This exacerbates the model bias toward too much 1979-2013 global warming while reducing the model bias toward too little Arctic sea ice retreat. These results are consistent with the sea ice sensitivity not being substantially influenced by volcanic eruptions, which would imply that the higher level of global warming caused by volcanoes should coincide with more sea ice retreat. This suggests that the reported improvement in simulated sea ice trends was largely an artifact of comparing simulations that had volcanic forcing with simulations that did not.

Acknowledgments. Without implying their endorsement, we are grateful to Sarah Gille, Art Miller, Paul Kushner, Neil Tandon, Frédéric Laliberté, Till Wagner, and John Fyfe for helpful comments and discussions. This work was supported by a National Science Foundation Graduate Research Fellowship and National Science Foundation Grants ARC-1107795 and OCE-1357078. We thank the climate modeling groups, the Program for Climate Model Diagnosis and Intercomparison, and the World Climate Research Programme's Working Group on Coupled Modelling for producing and making available the CMIP3 and CMIP5 multimodel datasets. Processed CMIP3 and CMIP5 data used in this study are available online at http://eisenman.ucsd.edu/code.html.

\section{APPENDIX}

\section{Methods}

We analyze 118 simulations of years 1979-2013 from 40 CMIP5 models (Taylor et al. 2012) with historical and RCP4.5 forcing as well 38 simulations from 19 CMIP3 models (Meehl et al. 2007) with historical and SRES A1B forcing. The time period we analyze is chosen based on the availability of sea ice observations at the time of analysis. We use monthly-mean fields to compute values of global-mean surface air temperature, sea ice extent, and sea ice area. Gridcell area fields are used for models that provide them in the CMIP archives; otherwise, we estimate the gridcell areas based on the reported gridbox vertices. For simplicity, in the distributions we treat each simulation as an ensemble member from an independent model, rather than considering which model each simulation comes from.

CMIP3 simulations were not used in this study when either (i) temperature and sea ice data were not both available during 1979-2013 or (ii) dates reported in the file did not match the filename in the CMIP3 archive. The following CMIP3 simulations each had at least one of these issues and were excluded: all runs of CSIRO Mk3.0; all runs of BCC-CM1; all runs of GISS-EH; CSIRO Mk3.5 runs 2 and 3; GISS-ER runs 2-9; all runs of INGV-ECHAM; and NCAR CCSM3 runs 3, 4, 8, and 9 (see http://www.ametsoc.org/PubsAcronymList for 
acronym expansions). We also exclude all runs of IAP FGOALS because the simulated sea ice extent in both hemispheres is approximately twice as large as any other CMIP3 simulation. IPSL-CM4 reported grid cells with sea ice concentrations greater than $100 \%$, which we replaced with $100 \%$. Finally, note that MRI-CGCM2.3.2a reported having volcanic forcing in the CMIP3 documentation, but several studies found that it did not actually appear to include volcanic forcing (Knutson et al. 2013; Sillmann et al. 2013). We therefore considered this model to have not included volcanic forcing.

This study uses the processed CMIP5 values from Rosenblum and Eisenman (2016), where processing details are given. In the analysis of trends during years 1900-2100, we use only 80 CMIP5 simulations because 38 of the simulations do not report model output during the entirety of this longer time period.

We use observed monthly-mean sea ice extent and area from the National Snow and Ice Data Center Sea Ice Index (Fetterer et al. 2002), which uses the NASA Team algorithm. Missing values are filled by linearly interpolating between the same month in the previous and following years. We use the Goddard Institute for Space Sciences Surface Temperature Analysis (GISTEMP; Hansen et al. 2010) for the observed annual-mean globalmean surface temperature data.

All trends are computed using ordinary least squares regressions with time. For the sea ice sensitivity, the annual or September sea ice trend is divided by the annual global-mean surface air temperature trend. This method of estimating the sea ice sensitivity is sometimes referred to as the "trend ratio" (Winton 2011). For the simulated effective sea ice trend, the simulated sea ice sensitivity is multiplied by the observed annual-mean global-mean surface temperature trend, as described in Rosenblum and Eisenman (2016). Note that for the observations, this leads to an effective sea ice trend which is equal to the actual sea ice trend. Winton (2011) suggests that total least squares (TLS) regression between ice and temperature leads to a slightly less biased estimate of the ice sensitivity, but we find that this has a relatively small influence on the results presented here. For example, when we compute the observed Arctic sea ice sensitivity using TLS regression instead of the trend ratio, the ice sensitivity increases from $-5.67 \times 10^{6}$ to $-5.69 \times 10^{6} \mathrm{~km}^{2} \mathrm{~K}^{-1}$.

\section{REFERENCES}

Arfeuille, F., D. Weisenstein, H. Mack, E. Rozanov, T. Peter, and S. Brönnimann, 2014: Volcanic forcing for climate modeling: A new microphysics-based data set covering years 1600-present. Climate Past, 10, 359-375, doi:10.5194/cp-10-359-2014.
Armour, K. C., I. Eisenman, E. Blanchard-Wrigglesworth, K. E. McCusker, and C. M. Bitz, 2011: The reversibility of sea ice loss in a state-of-the-art climate model. Geophys. Res. Lett., 38, L16705, doi:10.1029/2011GL048739.

Eisenman, I., 2010: Geographic muting of changes in the Arctic sea ice cover. Geophys. Res. Lett., 37, L16501, doi:10.1029/ 2010 GL043741.

Fetterer, F., K. Knowles, W. Meier, and M. Savoie, 2002 (updated 2014): Sea ice index. National Snow and Ice Data Center. Accessed June 2014. [Available online at http://nsidc.org/data/ g02135.html.]

Flato, G., and Coauthors, 2013: Evaluation of climate models. Climate Change 2013: The Physical Science Basis, T. F. Stocker et al., Eds., Cambridge University Press, 741-866, doi:10.1017/ CBO9781107415324.020.

Fyfe, J. C., 2006: Southern Ocean warming due to human influence. Geophys. Res. Lett., 33, L19701, doi:10.1029/ 2006 GL027247.

_ N. N. P. Gillett, and F. W. Zwiers, 2013: Overestimated global warming over the past 20 years. Nat. Climate Change, 3, 767769, doi:10.1038/nclimate1972.

Gregory, J. M., P. A. Stott, D. J. Cresswell, N. A. Rayner, C. Gordon, and D. M. H. Sexton, 2002: Recent and future changes in Arctic sea ice simulated by the HadCM3 AOGCM. Geophys. Res. Lett., 29, 2175, doi:10.1029/2001GL014575.

Hansen, J., R. Ruedy, M. Sato, and K. Lo, 2010: Global surface temperature change. Rev. Geophys., 48, RG4004, doi:10.1029/ 2010RG000345.

IPCC, 2013: Climate Change 2013: The Physical Science Basis. Cambridge University Press, 1535 pp.

Kay, J. E., M. M. Holland, and A. Jahn, 2011: Inter-annual to multidecadal Arctic sea ice extent trends in a warming world. Geophys. Res. Lett., 38, L15708, doi:10.1029/2011GL048008.

Knutson, T. R., F. Zeng, and A. T. Wittenberg, 2013: Multimodel assessment of regional surface temperature trends: CMIP3 and CMIP5 twentieth-century simulations. J. Climate, 26, 8709-8743, doi:10.1175/JCLI-D-12-00567.1.

Knutti, R., and J. Sedláček, 2012: Robustness and uncertainties in the new CMIP5 climate model projections. Nat. Climate Change, 3, 369-373, doi:10.1038/nclimate1716.

Kosaka, Y., and S.-P. Xie, 2013: Recent global-warming hiatus tied to equatorial Pacific surface cooling. Nature, 501, 403-407, doi:10.1038/nature12534.

Mahlstein, I., and R. Knutti, 2012: September Arctic sea ice predicted to disappear near $2^{\circ} \mathrm{C}$ global warming above present. J. Geophys. Res., 117, D06104, doi:10.1029/2011JD016709.

Marotzke, J., and P. M. Forster, 2015: Forcing, feedback and internal variability in global temperature trends. Nature, 517, 565-570, doi:10.1038/nature14117.

Massonnet, F., T. Fichefet, H. Goosse, C. M. Bitz, G. PhilipponBerthier, M. M. Holland, and P.-Y. Barriat, 2012: Constraining projections of summer Arctic sea ice. Cryosphere, 6, 1383-1394, doi:10.5194/tc-6-1383-2012.

Meehl, G. A., C. Covey, T. Delworth, M. Latif, B. McAvaney, J. F. B. Mitchell, R. J. Stouffer, and K. E. Taylor, 2007: The WCRP CMIP3 multimodel dataset: A new era in climatic change research. Bull. Amer. Meteor. Soc., 88, 1383-1394, doi:10.1175/ BAMS-88-9-1383.

Rayner, N. A., D. Parker, E. Horton, C. Folland, L. Alexander, D. Rowell, E. Kent, and A. Kaplan, 2003: Global analyses of sea surface temperature, sea ice, and night marine air temperature since the late nineteenth century. J. Geophys. Res., 108, 4407, doi:10.1029/2002JD002670. 
Santer, B. D., and Coauthors, 2014: Volcanic contribution to decadal changes in tropospheric temperature. Nat. Geosci., 7, 185-189, doi:10.1038/ngeo2098.

Schmidt, G. A., D. T. Shindell, and K. Tsigaridis, 2014: Reconciling warming trends. Nat. Geosci., 7, 158-160, doi:10.1038/ ngeo2105.

Segschneider, J., and Coauthors, 2013: Impact of an extremely large magnitude volcanic eruption on the global climate and carbon cycle estimated from ensemble Earth system model simulations. Biogeosciences, 10, 669-687, doi:10.5194/ bg-10-669-2013.

Sillmann, J., V. V. Kharin, X. Zhang, F. W. Zwiers, and D. Bronaugh, 2013: Climate extremes indices in the CMIP5 multimodel ensemble: Part 1. Model evaluation in the present climate. J. Geophys. Res. Atmos., 118, 1716-1733, doi:10.1002/jgrd.50203.

Stenchikov, G., T. L. Delworth, V. Ramaswamy, R. J. Stouffer, A. Wittenberg, and F. Zeng, 2009: Volcanic signals in oceans. J. Geophys. Res., 114, D16104, doi:10.1029/ 2008JD011673.

Stroeve, J., and D. Notz, 2015: Insights on past and future sea-ice evolution from combining observations and models. Global Planet. Change, 135, 119-132, doi:10.1016/j.gloplacha.2015.10.011.

, and _ 2016: Corrigendum to insights on past and future sea-ice evolution from combining observations and models [Glob. Planet. Change (2015) 119-132]. Global Planet. Change, 144, 270, doi:10.1016/j.gloplacha.2016.07.003.

M. M. Holland, W. Meier, T. Scambos, and M. Serreze, 2007: Arctic sea ice decline: Faster than forecast. Geophys. Res. Lett., 34, L09501, doi:10.1029/2007GL029703.

, V. Kattsov, A. Barrett, M. Serreze, T. Pavlova, M. Holland, and W. N. Meier, 2012: Trends in Arctic sea ice extent from CMIP5, CMIP3 and observations. Geophys. Res. Lett., 39, L16502, doi:10.1029/2012GL052676.
Swart, N. C., J. C. Fyfe, E. Hawkins, J. E. Kay, and A. Jahn, 2015: Influence of internal variability on Arctic sea-ice trends. Nat. Climate Change, 5, 86-89, doi:10.1038/nclimate2483.

Taylor, K. E., R. J. Stouffer, and G. A. Meehl, 2012: An overview of CMIP5 and the experiment design. Bull. Amer. Meteor. Soc., 93, 485-498, doi:10.1175/BAMS-D-11-00094.1.

Watanabe, M., Y. Kamae, M. Yoshimori, A. Oka, M. Sato, M. Ishii, T. Mochizuki, and M. Kimoto, 2013: Strengthening of ocean heat uptake efficiency associated with the recent climate hiatus. Geophys. Res. Lett., 40, 3175-3179, doi:10.1002/grl.50541.

Winton, M., 2011: Do climate models underestimate the sensitivity of Northern Hemisphere sea ice cover? J. Climate, 24, 39243934, doi:10.1175/2011JCLI4146.1.

Zanchettin, D., C. Timmreck, H.-F. Graf, A. Rubino, S. Lorenz, K. Lohmann, K. Krüger, and J. H. Jungclaus, 2012: Bi-decadal variability excited in the coupled ocean-atmosphere system by strong tropical volcanic eruptions. Climate Dyn., 39, 419-444, doi:10.1007/s00382-011-1167-1.

—, O. Bothe, H. F. Graf, S. J. Lorenz, J. Luterbacher, C. Timmreck, and J. H. Jungclaus, 2013: Background conditions influence the decadal climate response to strong volcanic eruptions. J. Geophys. Res. Atmos., 118, 4090-4106, doi:10.1002/ jgrd.50229.

, — C. Timmreck, J. Bader, A. Beitsch, H.-F. Graf, D. Notz, and J. H. Jungclaus, 2014: Inter-hemispheric asymmetry in the sea-ice response to volcanic forcing simulated by MPI-ESM (COSMOS-Mill). Earth Syst. Dyn., 5, 223-242, doi:10.5194/ esd-5-223-2014.

Zhong, Y., G. H. Miller, B. L. Otto-Bliesner, M. M. Holland, D. A. Bailey, D. P. Schneider, and A. Geirsdottir, 2011: Centennialscale climate change from decadally-paced explosive volcanism: A coupled sea ice-ocean mechanism. Climate Dyn., 37, 2373-2387, doi:10.1007/s00382-010-0967-z. 